\title{
Shanghai Port Carbon Emission Measurement Study
}

\author{
Ling Zhang \\ School of Transportation, Shanghai Maritime University, Shanghai, 201306, China
}

\begin{abstract}
Port carbon emission is a general term for greenhouse gas emissions generated by ports in production activities and by ships in port areas during navigation and berthing. Accurate measurement of port carbon emissions and analysis of the time series characteristics of port carbon emissions are the prerequisite and foundation for revealing the deep mechanism of port carbon emission changes, which is of great significance to China's port carbon emission reduction. The article will refer to the relevant carbon emission measurement process and methods, take Shanghai port during 2010-2019 as the research object, construct a carbon emission measurement model of Shanghai port, and quantitatively analyze the port carbon emission based on the measurement model and the collected data, and study the change trend and characteristics of carbon dioxide emission of Shanghai port, so as to further supplement and improve the carbon emission knowledge system of the port industry and promote China's port This will further improve the carbon emission knowledge system of the port industry and promote the sustainable development of China's ports.
\end{abstract}

Keywords: Carbon dioxide emissions, Port, Shanghai Port, Case study.

\section{Introduction}

In the wave of rapid global economic development, the natural environment on which human beings depend for survival has been seriously challenged. In order to comprehensively control greenhouse gas emissions such as carbon dioxide and cope with the adverse effects of global warming on human economy and society, countries around the world have been actively trying to set greenhouse gas emission limits or formulate guidance documents to reduce emissions in the past decades. In the National People's Congress of China in 2021, "carbon peaking" and "carbon neutral" were written into the government work report for the first time, and appeared in a number of important meetings of the central government, how to achieve low carbon emissions and net zero emissions has become the common concern of countries and local governments around the world. The focus. China's ports are the key energy-consuming units in the transportation industry and the high carbon emission areas in cities, and the realization of low-carbon port development is of great significance to the low-carbon economic development and ecological environmental protection of cities.

Shanghai port is located at the intersection of Yangtze River economic belt and coastal economic belt, and is a national comprehensive transportation corridor and an important node of domestic and international logistics, with the regional advantage of two-way radiation to both internal and external [1]. In 2005, Shanghai released the "Implementation Plan of Shanghai Port Dust Pollution Prevention and Management", followed by the "Shanghai Port Ship Pollution Prevention Measures", "Shanghai Green Port Three-Year Action Plan (2015-2017)" and "13th Five-Year Plan for Green Transportation". At the same time, low-carbon development work is carried out in the port area, including pilot shorebased (port-based) power supply for ships in port, pilot LNG power for river cargo ships, pilot exhaust gas treatment devices for ships, RTG "oil to electricity", natural gas trailers, old ship phase-out and renewal, etc. Shanghai is actively promoting the construction of low-carbon ports, and Shanghai Port has achieved certain results in energy saving and emission reduction. However, in the face of the double pressure of the complicated international political and economic situation and the increasing global air pollution, it becomes particularly important for port authorities to improve both the international competitiveness of these integrated facilities and their environmental performance, and how the port can achieve reasonable low-carbon development. In this chapter, we study the issues related to carbon emission of Shanghai port, establish a port carbon emission measurement model, and quantitatively analyze the trend and characteristics of carbon emission changes, in order to help enterprises and government understand the current situation of carbon emission of Shanghai port, solve the problems of energy saving and emission reduction of Shanghai port, and promote the construction of low-carbon port.

The current research on port carbon emission measurement has mainly studied and analyzed the calculation of Carbon Dioxide emissions and carbon footprint of ports, port terminals and ships in port areas. The Spanish port of Gijón (2002) was one of the first ports in the world to calculate its carbon footprint, detecting all direct and indirect sources of emissions, making it possible to develop strategies to reduce emissions, and again between 2004 and 2008[2]. Villalba and Gemechu [3] used $\mathrm{CO}_{2}$ emissions per unit of cargo or per unit of passenger as a basis for calculations and policy development, among others, to calculate the total $\mathrm{CO} 2$ emissions of the Port of Barcelona in 2008 and found that half of the GHG emissions in the port area were attributable to ship movements (maritime emissions) and the other half were attributable to port, land-related activities (land-based emissions). Misra et al. [4] estimated the carbon footprint of Chennai Port (India) for 2014-2015 based on the WPCI guidelines, detailing the GHG emissions inventory of Chennai Port (India), which includes various facilities of this port managed by Chennai Port as well as housing colonies and fishing ports. Air Emissions Inventory Methodology Used by Archana et al. to Calculate Carbon Emissions from the Port of Long Beach, USA. Van Duin and Greelings [5]provide insights into terminal container handling and transshipment processes, developing a bottom-up approach that calculates the contribution of these processes to $\mathrm{CO}_{2}$ 
emissions from container terminals and validating the application through $95 \%$ of the maritime and inland container terminals in the Netherlands. Budiyanto et al. [6]calculated the energy consumption and $\mathrm{CO}_{2}$ emissions of two container terminals in parallel and vertical layouts using a movement pattern based on the number of movements and movement distance of each container handling equipment to estimate $\mathrm{CO}_{2}$ emissions, proving that both layouts are suitable for the sustainability of future terminals. Young-Tae Chang et al. [7]calculated ship emissions from the port of Incheon, Korea, based on the types and activities of ships from arrival to docking, cargo handling and departure, and compared the bottom-up and top-down approaches and found significant differences. Goldsworthy et al. [8] used AIS data to develop a model describing ship movements and operating patterns to provide a comprehensive analysis of ship engine emissions over a wide area containing multiple ports, and applied it to the Australian coast and Australian ports. Tichavska and Tovar [9] used AIS data and steam emission models to calculate emissions from cruise ships and ferries in the port of Las Palmas. Winnes et al. [10]studied different types of emission reduction measures for different types of ships and different parts of the port area, conducted a case study of ship traffic in the port of Gothenburg under different scenarios, and made projections of ship emissions in the port area for 2030. Olukanni and Esu [11]estimated greenhouse gas emissions from vessel operations at Lagos and Tin Can ports in Nigeria using a bottom-up approach based on the characteristics of individual vessels and their movements upon arrival. In addition, other studies of ship emissions based on AIS data include Jalkanen et al[12]; Olesen et al[13]; Pitana et al[14]; Jalkanen et al[15]; Ng et al[16].

The structure of this paper is as follows: in the second part, the carbon emission measurement model of Shanghai port is constructed by drawing on the measurement methods of other literature; in the third part, the required data and information are found through research, and the carbon emissions in the three ranges are measured and analyzed; in the fourth part, the whole paper is concluded.

\section{Construction of Carbon Emission Measurement Model for Shanghai Port}

\subsection{Measurement Basis}

At present, there are no unified standards, guidelines or accounting tools for port greenhouse gas accounting internationally. Analyzing the research results of domestic and foreign scholars on port Carbon Dioxide emissions, the main internationally recognized and widely used reference documents are the Greenhouse Gas Protocol (GHG Protocol) and the Air Quality and Greenhouse Gas Tool (AQGT). This paper mainly relies on the Greenhouse Gas Protocol to make a detailed measurement of $\mathrm{CO}_{2}$ emissions from Shanghai port through the emission factor method, aiming to help the port and related units to identify the problems and emission reduction countermeasures in their process of reducing $\mathrm{CO}_{2}$ emissions.

The Greenhouse Gas Protocol, jointly developed by the World Resources Institute (WRI) and the World Business Council for Sustainable Development (WBCSD), provides guidelines for the quantification and management of $\mathrm{CO}_{2}$ emissions, and its findings are often the basis for effective analysis of greenhouse gas emissions by governments and businesses, etc. It has become the most widely used tool for accounting for $\mathrm{CO}_{2}$ emissions by governments and businesses around the world[17].

\subsection{Measurement Boundary, Scope and Emission Sources}

\subsubsection{Measurement Boundary}

As shown in Figure 1, the study area of this study is the Port of Shanghai, including the port area within the Shanghai municipality and the Yangshan Deepwater Port. Longitude range from $120.5^{\circ} \mathrm{E}$ to $122.3^{\circ} \mathrm{E}$ and latitude range from $30.5^{\circ} \mathrm{N}$ to $32^{\circ} \mathrm{N}[18]$. The boundary of port carbon emission measurement is basically consistent with the statistical boundary stipulated by Shanghai energy statistical reporting system, including direct and indirect emissions from energy consumption of loading and unloading activities, auxiliary activities and ship activities in the port area of Shanghai port. Located at the mouth of Yangtze River, Shanghai Port is a transportation hub port on the southeast coast of China and one of the world's famous ports with a well-developed shipping and service industry. The largest port area of the Port of Shanghai is Waigaoqiao Port Area, located on the south bank of the South Port Channel at the mouth of the Yangtze River. Other large ports in Shanghai include Wusong Terminal, Luojing Ore Terminal, Yangshan Deepwater Port and other terminals along the Yangtze River.

\subsubsection{Measurement Range}

In port GHG accounting, the measurement boundary needs to be determined first, which is also the confirmation of the data boundary and the basis for accurate calculation of carbon emissions. According to the above determination of the measurement boundary, the geographical boundary of Shanghai port is set as the accounting boundary in this paper. The $\mathrm{CO}_{2}$ emission sources of the port mainly include the following types of emissions.

Scope 1: Watch direct emissions. Direct emissions generated by stationary and mobile combustion during the live watching process, or direct emissions that cannot be caused by direct emissions, are directly controlled by the management of the viewing experience and some operations.

Scope 2: Pay attention to the self-emission of the energy obtained by life in the eyes, and within the range of the port area outside the source. For example, look at the consumption and emissions of heating, cooling, electricity or heat. The purchase is not included in this scope.

Scope 3: Other emissions are poor. Related to amusement parks or other outdoor emissions or other (see outdoor entertainment generation), they are in: port control activities will generate outdoor private emissions. This scope also includes emissions from employee commuting or travel[17].

\subsubsection{Sources of Carbon Dioxide Emissions}

According to the above-mentioned port carbon emission measurement range classification, the emission sources can be divided into the following three categories: direct emission source 1 (port vehicles, loading and unloading equipment, etc.), indirect emission source 2 (power grid, etc.), indirect emission source 3 (sea Ships, domestic ships, etc.).

The emission sources of Scope 1 belong to port enterprises, and the emission sources of Scope 2 and 3 do not belong to port enterprises. The difference between Scope 2 and Scope 3 is that in Scope 2, the places where emissions are generated are outside the port area, while in Scope 3, emissions are generated within the port area. It should be noted that since 
the emissions from port employees' commuting or business trips have minimal impact on the port's carbon emissions calculations, they can be roughly ignored; warehouses and storage yards used by the port itself need to be classified as indirect emission sources 2 and leased The part given to tenants needs to be classified as an indirect emission source3.

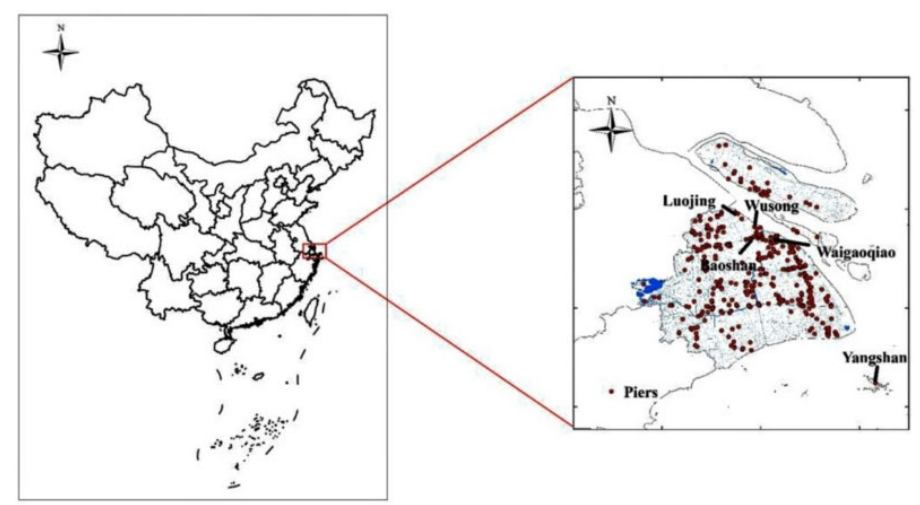

Figure 1. Location map of Shanghai's terminals and major ports

\subsection{Modeling the $\mathrm{CO}_{2}$ emissions of Shanghai Port}

According to the actual situation of Shanghai port and the boundary and scope limits, it is known that the scope 1 emissions are the sum of carbon dioxide emissions from all fuel combustion in the enterprise, the scope 2 emissions are the sum of carbon emissions from the consumption of electricity and heat in the enterprise, and the scope 3 emissions are the total carbon dioxide emissions from ship activities within the port area. Therefore, the actual total carbon emission of Shanghai port is the sum of Scope 1, Scope 2 and Scope 3 emissions, so the following expression is obtained.

$$
E^{t}=E_{f}^{t}+E_{e \& h}^{t}+E_{v}^{t}
$$

In the expression, $\mathrm{E}^{t}$ denotes the total carbon emissions of the port in year $\mathrm{t}$; $E_{\mathrm{f}}^{t}$ denotes total carbon emissions from fuel combustion in year $\mathrm{t} ; E_{\mathrm{e} \& \mathrm{~h}}^{t}$ denotes the total carbon emission of electricity and heat consumption in year $\mathrm{t} ; E_{v}^{t}$ denotes the total carbon emissions from ship activities in the port area in year $\mathrm{t}$; All variables involved in the above are in tons.

\subsubsection{Shanghai Port Fuel Combustion Carbon Emissions}

The carbon emissions from the combustion of each fossil fuel can be obtained by multiplying the actual activity of that fuel with the corresponding emission factor (which represents the $\mathrm{CO}_{2}$ emission factor per unit of production or consumption activity), which is expressed as follows.

$$
\mathrm{E}_{\mathrm{f}}^{\mathrm{t}}=\sum \mathrm{AD}_{\mathrm{i}}^{\mathrm{t}} \times \mathrm{FC}_{\mathrm{i}}^{\mathrm{t}}
$$

In the expression, $\mathrm{AD}_{i}^{t}$ denotes the activity of the $\mathrm{i}$-th fuel burned in year $\mathrm{t}$, in $\mathrm{kJ} ; \mathrm{FC}_{i}^{t}$ denotes the $\mathrm{CO}_{2}$ emission factor in tons of $\mathrm{CO}_{2} /$ million $\mathrm{KJ}$ for fuel combustion in year i of year t.

Fuel activity is the activity of a fuel is the product of the net consumption of that fuel in the accounting range and the average low-level heat content, and the expression is shown below.

$$
\mathrm{AD}_{\mathrm{i}}^{\mathrm{t}}=\sum \mathrm{FC}_{\mathrm{i}}^{\mathrm{t}} \times \mathrm{NCV}_{\mathrm{i}}^{\mathrm{t}}
$$

In the expression, $\mathrm{FC}_{i}^{t}$ denotes the net consumption of the ith fuel burned in the year $\mathrm{t}$ in tons; $\mathrm{NCV}_{i}^{t}$ denotes the average low-level heat output of the ith fuel in the year $t$ in kilojoules per kilogram.

The $\mathrm{CO}_{2}$ emission factor of a fuel is the product of the carbon content per unit calorific value of the fuel, the carbon oxidation rate and the fixed ratio (i.e., the ratio of the relative atomic masses of carbon dioxide to carbon) in the accounting range, expressed as follows.

$$
\mathrm{FC}_{\mathrm{i}}^{\mathrm{t}}=\sum \mathrm{CC}_{\mathrm{i}}^{\mathrm{t}} \times \mathrm{OF}_{\mathrm{i}}^{\mathrm{t}} \times \frac{44}{12}
$$

In the expression, $\mathrm{CC}_{i}^{t}$ indicates the carbon content per unit calorific value of the ith fuel burned in year $t$, expressed in tons of carbon per $\mathrm{kJ} ; \mathrm{OF}_{i}^{t}$ indicates the carbon oxidation rate of the ith fuel burned in year $t$, expressed in $\% ; 44 / 12$ characterizes the ratio of carbon dioxide to the relative atomic mass of carbon.

From Eqs. (3) and (4), Eq. (2) can be rearranged to obtain Eq. (5) as follows.

$$
\mathrm{E}_{\mathrm{f}}^{\mathrm{t}}=\sum \mathrm{FC}_{\mathrm{i}}^{\mathrm{t}} \times \mathrm{NCV}_{\mathrm{i}}^{\mathrm{t}} \times \mathrm{CC}_{\mathrm{i}}^{\mathrm{t}} \times \mathrm{OF}_{\mathrm{i}}^{\mathrm{t}} \times \frac{44}{12}
$$

Note that the missing $\mathrm{CO}_{2}$ emission factors are based on the default values of the IPCC Guidelines for National Greenhouse Gas Inventories (2006).

For rough estimation, the fossil fuel consumption is converted to total fuel consumption in standard coal, and the conversion formula is Eq. (6).

$$
\mathrm{E}_{\mathrm{f}}^{\mathrm{t}}=\sum \mathrm{FC}^{\mathrm{t}} \times \mathrm{EC}_{\mathrm{s}}
$$

In the expression, $\mathrm{FC}^{t}$ denotes the conversion of port fuel consumption to standard coal consumption in year $\mathrm{t} ; \mathrm{EC}_{\mathrm{s}}$ denotes the standard coal emission factor, and the default value is taken as $2.7725 \mathrm{tCO}_{2} / \mathrm{t}$ according to the IPCC Guidelines for National Greenhouse Gas Inventories (2006)[19]

\subsubsection{Carbon Emissions from Electricity/Heat Consumption at Shanghai Port}

For the carbon dioxide emissions generated by the purchased power consumption link of the port enterprise, it can be obtained by multiplying the purchased power/heat by the average power/heat emission factor of the regional grid, whose expression Eq. (7).

$$
\mathrm{E}_{\mathrm{e}}^{\mathrm{t}}=\sum \mathrm{AD}_{\mathrm{e}}^{\mathrm{t}} \times \mathrm{EC}_{\mathrm{e}}^{\mathrm{t}}
$$


$\mathrm{AD}_{\mathrm{e}}^{t}$ denotes purchased power in $\mathrm{kWh}$ in year t. $\mathrm{EC}_{\mathrm{e}}^{t}$ denotes the average power supply emission factor in tons of $\mathrm{CO}_{2} / \mathrm{kWh}$ for the regional grid in year $\mathrm{t}$.

Similarly the expression for $\mathrm{CO}_{2}$ emissions from the purchase of thermal power consumption is Eq. (8)

$$
\mathrm{E}_{\mathrm{h}}^{\mathrm{t}}=\sum \mathrm{AD}_{\mathrm{h}}^{\mathrm{t}} \times \mathrm{EC}_{\mathrm{h}}^{\mathrm{t}}
$$

where $\mathrm{AD}_{h}^{t}$ denotes purchased heat in year $\mathrm{t}$ in $\mathrm{KJ}$, and $\mathrm{EC}_{h}^{t}$ denotes the average power supply emission factor of the regional grid in year $\mathrm{t}$ in tons $\mathrm{CO}_{2} / \mathrm{KJ}$.

From the above analysis, the total $\mathrm{CO}_{2}$ emissions in scope 2 can be expressed as Eq. (9).

$$
\mathrm{E}_{\mathrm{e} \& \mathrm{~h}}^{\mathrm{t}}=\sum \mathrm{AD}_{\mathrm{e}}^{t} \times \mathrm{EC}_{\mathrm{e}}^{t}+\sum \mathrm{AD}_{\mathrm{h}}^{\mathrm{t}} \times \mathrm{EC}_{\mathrm{h}}^{\mathrm{t}}
$$

\subsubsection{Carbon Emissions from Ship Activities in Shanghai Port Area}

Since data related to tonnage and time in port of vessels operating within the port area are usually difficult to obtain, especially the operation of charterers or other participants within the port area is difficult to accurately grasp, it is necessary to conduct detailed analysis of available statistical data to ensure the reliability and completeness of the data, etc. when calculating emissions from this part.

Carbon Dioxide emissions from ship activities within the port area can be measured by referring to C. S. Peng et al [17].

$$
\mathrm{E}_{\mathrm{v}}^{\mathrm{t}}=\frac{\mathrm{FC}_{\mathrm{f}}^{\mathrm{t}} \times \mathrm{EC}_{\mathrm{f}}^{\mathrm{t}}}{1000}
$$

Here $F C_{f}^{t}$ denotes the total fuel consumption of ships arriving in port in year t, in tons; $E C_{f}^{t}$ is the corresponding carbon emission factor, in tons of $\mathrm{CO}_{2} / \mathrm{t}$.

And because the total fuel consumption of the arriving ships is obtained by the product of the average stopping time of the ships in port, the fuel consumption rate and the number of arriving ships, the expression is therefore the formula (11).

$$
\mathrm{E}_{\mathrm{v}}^{\mathrm{t}}=\frac{\sum_{\mathrm{j}=1}^{\mathrm{m}}\left[\left(\sum_{\mathrm{i}}^{\mathrm{n}} \mathrm{t}_{\mathrm{i}} / 24 \times \mathrm{F}_{\mathrm{j}}\right) \times \mathrm{N}_{\mathrm{j}}\right]}{1000} \times \mathrm{EC}_{\mathrm{f}}
$$

In Equation (11), $\mathrm{m}$ indicates the number of ship types active within the geographical boundaries of the port; $n$ indicates the number of ship activity types; $i$ indicates the order of ship activity types; $\mathrm{j}$ indicates the order of ship types; $t_{i}$ indicates the time required to complete the type $\mathrm{i}$ activities in port, in hours; $F_{j}$ represents the fuel consumption rate of type $\mathrm{j}$ ships in port activities $(\mathrm{t} / \mathrm{d}) ; N_{j}$ indicates the total number of the jth type of ship; $E C_{f}$ indicates the corresponding emission factor of the fuel used by the ship, in tons of $\mathrm{CO}_{2} / \mathrm{t}$.

\section{Shanghai Port Carbon Emission Estimation}

\subsection{Related Data Collection}

Shanghai port mainly includes the south coast of the municipal Yangtze River mouth, both sides of the Huangpu River and the north coast of Hangzhou Bay, Chongming Island, Changxing Island, Heng Sha Island Yan'an, Yangshan deep-water port area, and Shanghai inland port area. In terms of natural conditions, Shanghai has a subtropical maritime monsoon climate, which is influenced by alternating winter and summer winds, with four distinct seasons and warm and rainy seasons throughout the year, and has superior location conditions [1]. In terms of hardware facilities, by the end of 2019 , the coastal port of Shanghai port had 1,957 berths with a total length of 107,000 meters, including 185 10,000-ton berths; the cargo throughput of Shanghai port was $716,770,000$ tons, down $1.88 \%$ year-on-year, and the container throughput was $43,310,000$ TEU, up $3.09 \%$ yearon-year.

\subsubsection{Shanghai Port Energy Consumption}

Table 1 shows the statistical tables of cargo and container throughput of Shanghai Port from 2010 to 2019, which are compiled based on the data released by the Ministry of Transport.

Table 2, Table 3 and Table 4 show the energy consumption and corresponding growth rate of diesel, fuel oil and electricity of Shanghai Port Group from 2010 to 2019, respectively; the data of enterprise fossil fuel consumption and net purchased electricity are obtained from the Sustainable Development Report of Shanghai Group, statistical tables of production energy consumption of each port area, Shanghai Statistical Yearbook, etc. in each year; according to the statistical data, we can know that the main fossil fuels of Shanghai Port include Diesel fuel, fuel oil, etc., of which diesel fuel consumption accounts for a higher proportion; the types of energy consumption include diesel fuel, fuel oil, electricity and clean energy such as natural gas, which has started to become popular in recent years, etc. However, since the annual consumption of LNG is not large, it is not included in the calculation of this paper.

Table 1. 2010-2019 Shanghai Port Cargo and Container Throughput Statistics

\begin{tabular}{|c|c|c|c|c|}
\hline Year & Cargo throughput (million tons) & YOY\% & $\begin{array}{c}\text { Container throughput (million } \\
\text { TEU) }\end{array}$ & YOY\% \\
\hline 2010 & 65,339 & $10.36 \%$ & 2,907 & $16.28 \%$ \\
\hline 2011 & 72,758 & $11.35 \%$ & 3,174 & $9.18 \%$ \\
\hline 2012 & 73,559 & $1.10 \%$ & 3,253 & $2.49 \%$ \\
\hline 2013 & 77,574 & $5.46 \%$ & 3,362 & $3.35 \%$ \\
\hline 2014 & 75,529 & $-2.64 \%$ & 3,529 & $4.97 \%$ \\
\hline 2015 & 71,740 & $-5.02 \%$ & 3,654 & $3.54 \%$ \\
\hline 2016 & 70,177 & $-2.18 \%$ & 3,713 & $1.61 \%$ \\
\hline 2017 & 75,072 & $6.98 \%$ & 4,018 & $8.21 \%$ \\
\hline 2018 & 73,048 & $-2.70 \%$ & 4,201 & $4.55 \%$ \\
\hline 2019 & 71,677 & $-1.88 \%$ & 4,331 & $3.09 \%$ \\
\hline
\end{tabular}


Table 2. 2010-2019 SIPG diesel energy consumption and growth rate

\begin{tabular}{|c|c|c|c|}
\hline Year & Diesel fuel(tons) & YOY\% & CAGR \\
\hline 2010 & 123,852 & $/$ & $/$ \\
\hline 2011 & 130,139 & $5.08 \%$ & $5.08 \%$ \\
\hline 2012 & 127,066 & $-2.36 \%$ & $1.29 \%$ \\
\hline 2013 & 122,260 & $-3.78 \%$ & $-0.43 \%$ \\
\hline 2014 & 120,324 & $-1.58 \%$ & $-0.72 \%$ \\
\hline 2015 & 110,763 & $-7.95 \%$ & $-2.21 \%$ \\
\hline 2016 & 102,549 & $-7.42 \%$ & $-3.10 \%$ \\
\hline 2017 & 94,507 & $-7.84 \%$ & $-3.79 \%$ \\
\hline 2019 & 88,873 & $-5.96 \%$ & $-4.06 \%$ \\
\hline
\end{tabular}

Table 3. 2010-2019 Shanghai SIPG Group's fuel oil energy consumption and growth rate

\begin{tabular}{|c|c|c|c|}
\hline Year & Fuel oil(tons) & YOY\% & CAGR \\
\hline 2010 & 53,608 & $/$ & $/$ \\
\hline 2011 & 56,692 & $5.75 \%$ & $5.75 \%$ \\
\hline 2012 & 55,628 & $-1.88 \%$ & $1.87 \%$ \\
\hline 2013 & 57,760 & $3.83 \%$ & $2.52 \%$ \\
\hline 2014 & 70,955 & $22.84 \%$ & $7.26 \%$ \\
\hline 2015 & 65,965 & $-7.03 \%$ & $4.24 \%$ \\
\hline 2016 & 63,687 & $-3.45 \%$ & $2.91 \%$ \\
\hline 2017 & 66,879 & $5.01 \%$ & $3.21 \%$ \\
\hline 2019 & 74,100 & $10.80 \%$ & $4.13 \%$ \\
\hline
\end{tabular}

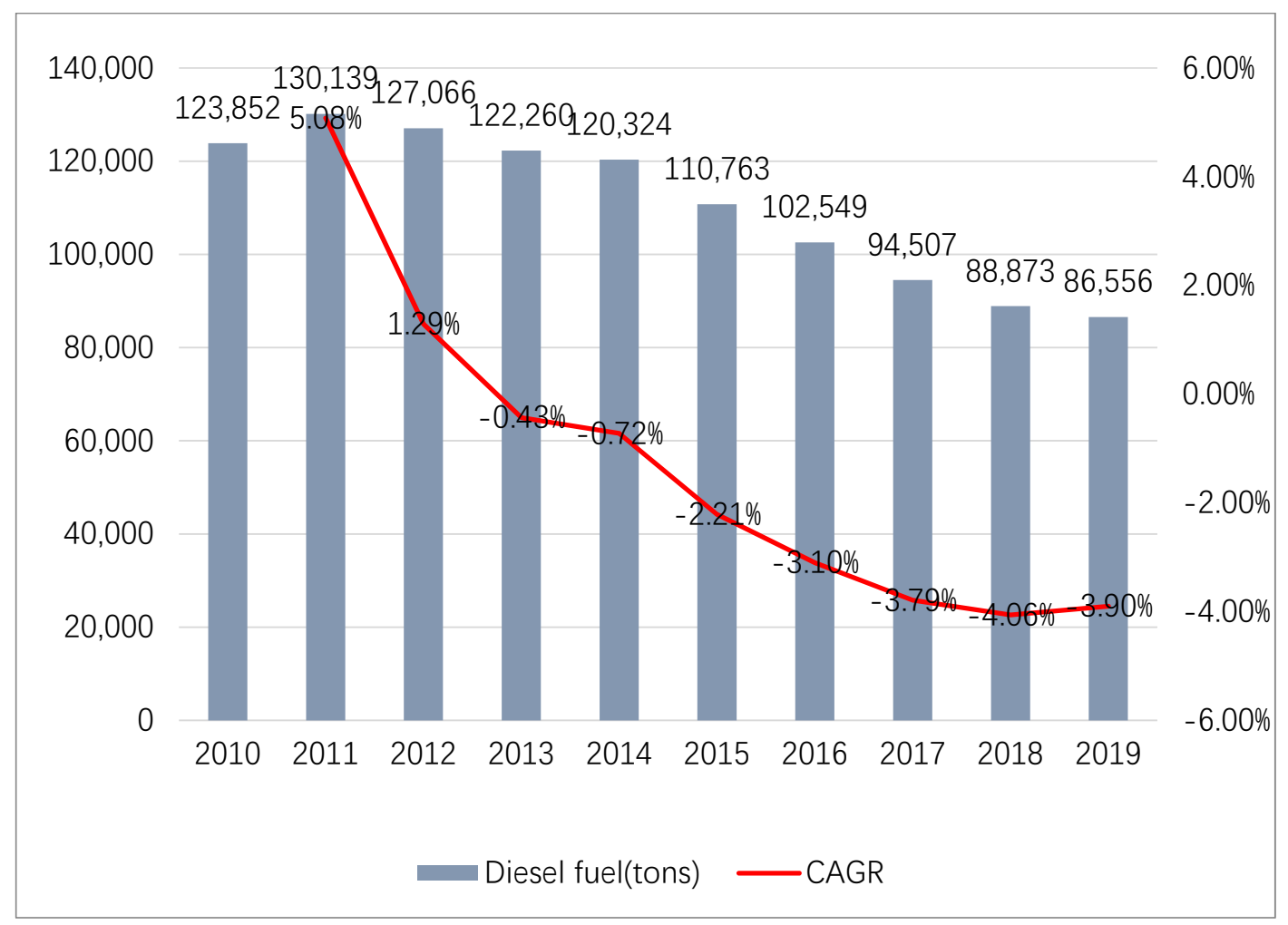

Figure 2. 2010-2019 Shanghai SIPG diesel energy consumption and compound growth rate trend chart 


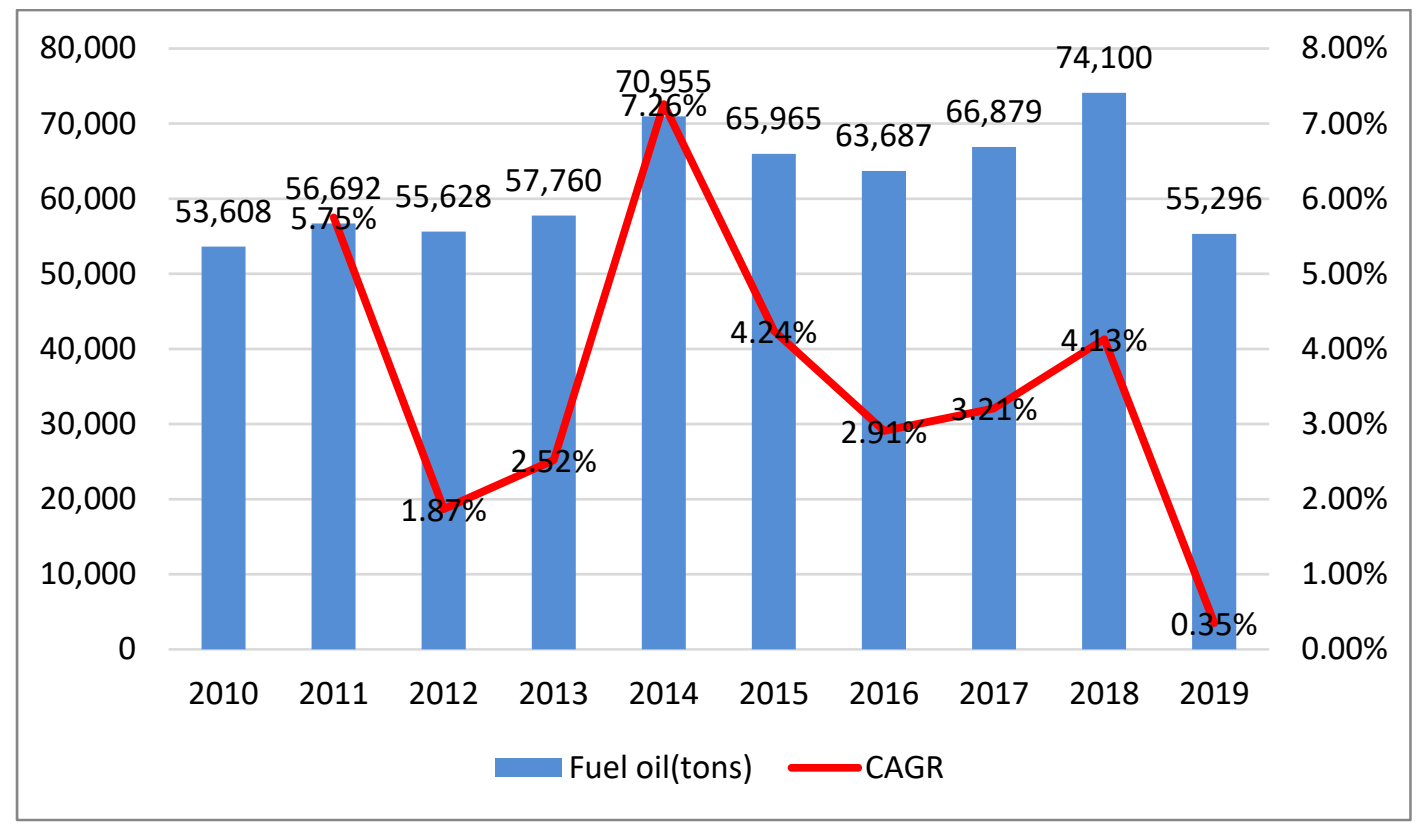

Figure 3. 2010-2019 Shanghai SIPG Group's fuel oil energy consumption and compound growth rate trend chart

Table 4. 2010-2019 Shanghai SIPG Electric Power Energy Consumption and Growth Rate

\begin{tabular}{|c|c|c|c|}
\hline Year & Electricity (million $\mathrm{kWh})$ & YOY\% & CAGR \\
\hline 2010 & 30,542 & $/$ & $/$ \\
\hline 2011 & 34,495 & $12.94 \%$ & $12.94 \%$ \\
\hline 2012 & 36,085 & $4.61 \%$ & $8.70 \%$ \\
\hline 2013 & 35,961 & $-0.34 \%$ & $5.60 \%$ \\
\hline 2014 & 35,682 & $-0.78 \%$ & $3.97 \%$ \\
\hline 2015 & 38,732 & $8.55 \%$ & $4.87 \%$ \\
\hline 2016 & 39,320 & $1.52 \%$ & $4.30 \%$ \\
\hline 2017 & 40,621 & $3.31 \%$ & $4.16 \%$ \\
\hline 2018 & 41,002 & $0.94 \%$ & $3.75 \%$ \\
\hline 2019 & 47,396 & $15.59 \%$ & $5.00 \%$ \\
\hline
\end{tabular}

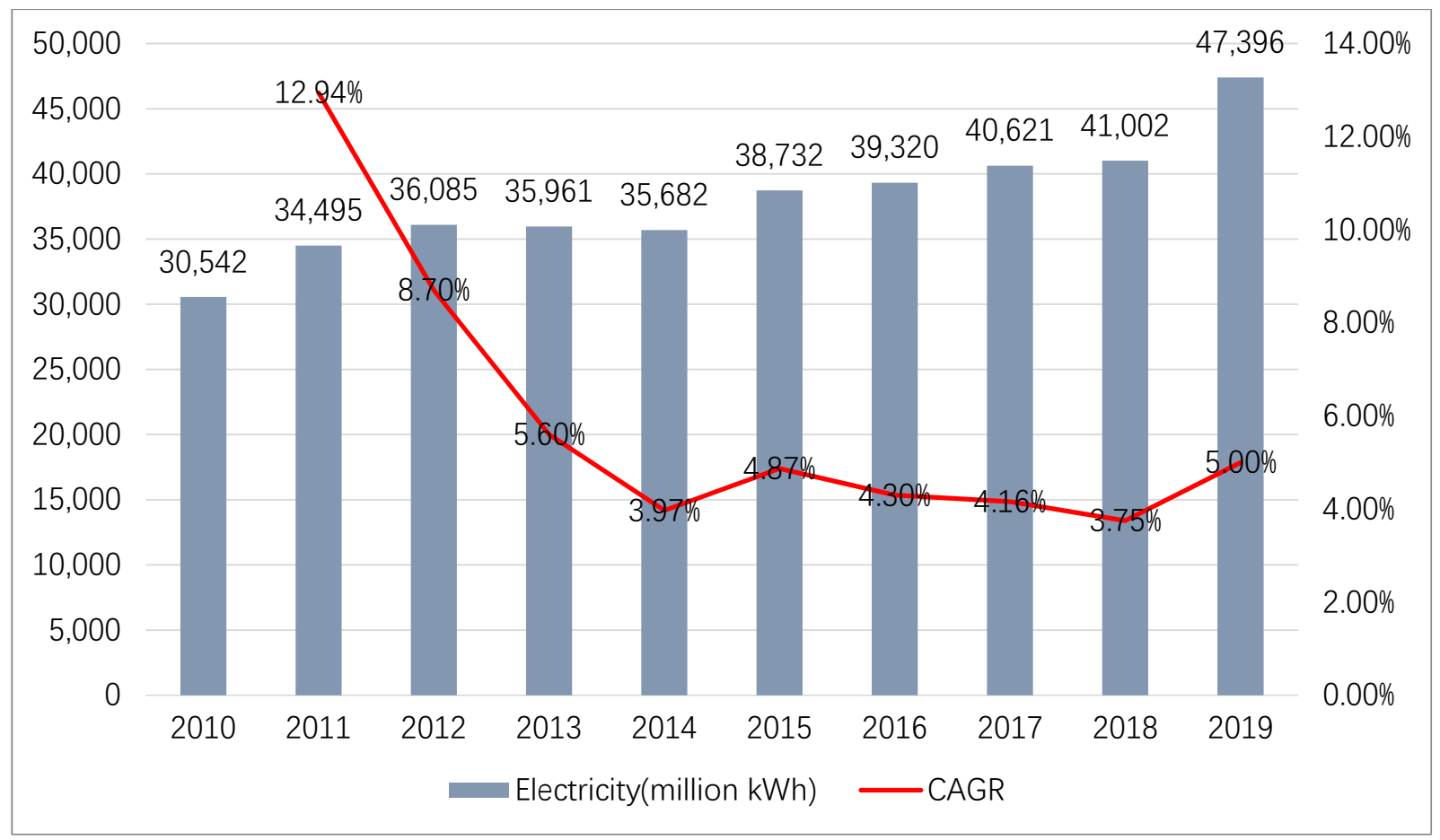

Figure 4. 2010-2019 Shanghai SIPG Electric Power Energy Consumption and Compound Growth Rate Trend Chart 
Table 5. Default values of fossil fuel related parameters

\begin{tabular}{|c|c|c|c|}
\hline Year & $\begin{array}{l}\text { Carbon content per unit } \\
\text { calorific value }(\mathrm{t}-\mathrm{C} / \mathrm{TJ})\end{array}$ & Low calorific value $\left(10^{3 *} \mathrm{KJ} / \mathrm{Kg}\right)$ & $\begin{array}{c}\text { Carbon oxidation } \\
\text { rate }\end{array}$ \\
\hline Diesel fuel & 20.2 & 43.3 & 0.98 \\
\hline Fuel oil & 21.1 & 40.2 & 0.98 \\
\hline
\end{tabular}

\subsubsection{Emission Factors}

Shanghai Port is located in the East China region, and Table 6 shows the grid baseline carbon emission factors conjunctures for 2010-2019, where 2018 and 2019 are the grid baseline emission factors for the East China region of the emission reduction project, and therefore will be smaller compared to 2010-2017. Table 7 shows the carbon emission factor and the discounted standard coal factor for energy.

Table 6. 2010-2019 East China Regional Power Grid Baseline Emission Factor Results

\begin{tabular}{|c|c|c|}
\hline Year & $\mathrm{EF}_{\text {grid, oM, } \mathrm{y}(\mathrm{tCO} / \mathrm{MWh})}$ & $\mathrm{EF}_{\text {grid, } \mathrm{BM}, \mathrm{y}\left(\mathrm{tCO} / \mathrm{MWh}_{2}\right)}$ \\
\hline 2010 & 0.8592 & 0.6789 \\
\hline 2011 & 0.8367 & 0.6622 \\
\hline 2012 & 0.8244 & 0.6889 \\
\hline 2013 & 0.8100 & 0.7125 \\
\hline 2014 & 0.8095 & 0.6861 \\
\hline 2015 & 0.8112 & 0.5945 \\
\hline 2016 & 0.8086 & 0.5483 \\
\hline 2017 & 0.8046 & 0.4923 \\
\hline 2018 & 0.7937 & 0.3834 \\
\hline & 0.7921 & 0.3870 \\
\hline
\end{tabular}

Table 7. Carbon emission factor and discounted standard coal factor for energy

\begin{tabular}{|c|c|c|}
\hline Type of energy & Carbon emission factors & Discount factor for standard coal \\
\hline Diesel fuel & 0.5921 & 1.4571 \\
\hline Fuel oil & 0.6185 & 1.4286 \\
\hline Electricity & Reference Table 4 & 0.1229 \\
\hline
\end{tabular}

\subsubsection{Ship-related Data}

At present, there are limited studies conducted in China on the emission factors of diesel engines in service, so this paper will refer to the emission factors in the U.S. ship emission inventory[20].

In the past decade, the cargo throughput of Shanghai port has been rising, and the container throughput has been the first in the world for ten consecutive years. Diesel fuel consumption decreases year by year, from 123,900 tons in 2010 to 86,600 tons in 2019 , with an average annual decrease of $3.90 \%$; the change in each year is large, with positive growth only in 2011 and 2012, with average annual growth rates of $5.08 \%$ and $1.29 \%$, respectively; and remains negative for eight consecutive years from 2012 to 2019.
Fuel oil consumption has shown an overall upward trend. The consumption has declined in 201, 2015 and 2019, and the rate in 2019 has shrunk by $22 \%$ and decreased by $25.38 \%$. The consumption of fuel oil reached its peak in 2018, with a total consumption of 7.41 tons. The overall upward trend is also optimistic, with the largest volatility in 2019 , with a forecast growth of $15.59 \%$.

\subsection{Shanghai Port Carbon Emission Calculation and Analysis}

According to the historical port data and the Shanghai port carbon emission calculation model, the carbon emissions in each range are calculated, as shown in Table 8.

Table 8. 2010-2019 SIPG Group's three types of energy consumption carbon emissions and total total

\begin{tabular}{|c|c|c|c|c|c|c|c|}
\hline Year & $\begin{array}{c}\text { Diesel } \\
\text { fuel(tons) }\end{array}$ & Fuel oil(tons) & $\begin{array}{c}\text { Electricity(tons } \\
\text { ) }\end{array}$ & Ship(tons) & $\begin{array}{c}\text { Total carbon } \\
\text { emissions(ton } \\
\text { s) }\end{array}$ & $\begin{array}{c}\text { Cargo } \\
\text { throughput(mi } \\
\text { llion tons) }\end{array}$ & $\begin{array}{c}\text { Carbon } \\
\text { emissions per } \\
\text { unit of cargo } \\
\text { throughput(to } \\
\text { ns/million } \\
\text { tons) }\end{array}$ \\
\hline 2010 & $73,332.77$ & $33,156.55$ & $262,416.86$ & $594,778.53$ & $963,684.71$ & $65,339.00$ & 14.75 \\
\hline 2011 & $77,055.30$ & $35,064.00$ & $288,619.67$ & $548,543.96$ & $949,282.93$ & $72,758.00$ & 13.05 \\
\hline 2012 & $75,235.78$ & $34,405.92$ & $297,484.74$ & $538,414.05$ & $945,540.49$ & $73,559.00$ & 12.85 \\
\hline 2013 & $72,390.15$ & $35,724.56$ & $291,284.10$ & $542,689.38$ & $942,088.19$ & $77,574.00$ & 12.14 \\
\hline 2014 & $71,243.84$ & $43,885.67$ & $288,845.79$ & $595,715.08$ & $999,690.38$ & $75,529.00$ & 13.24 \\
\hline 2015 & $65,582.77$ & $40,799.35$ & $314,193.98$ & $578,278.26$ & $998,854.36$ & $71,740.00$ & 13.92 \\
\hline 2016 & $60,719.26$ & $39,390.41$ & $317,941.52$ & $578,607.37$ & $996,658.56$ & $70,177.00$ & 14.20 \\
\hline 2017 & $55,957.59$ & $41,364.66$ & $326,836.57$ & $600,927.08$ & $1,025,085.90$ & $75,072.00$ & 13.65 \\
\hline 2018 & $52,621.70$ & $45,830.85$ & $330,063.01$ & $619,543.85$ & $1,048,059.41$ & $73,048.00$ & 14.35 \\
\hline 2019 & $51,249.81$ & $34,200.58$ & $381,348.22$ & $597,322.58$ & $1,064,121.19$ & $71,677.00$ & 14.85 \\
\hline
\end{tabular}


The measurement results show that the overall carbon emissions of Shanghai port in the past ten years are slowly increasing, from 963,700 tons in 2010 to $1,064,100$ tons in 2019 , with an average annual growth rate of $1.11 \%$. The variation of the growth rate from year to year is large. in 2019, the carbon emissions of the Port of Shanghai exceeded one million to $1,064,100$ tons. However, with the outbreak of COVID-19 at the end of 2019, human activities show a trend of large-scale curtailment, and the domestic and foreign energy consumption demand also decreases, which makes the port $\mathrm{CO}_{2}$ emissions controlled to a large extent. On the other hand, the further development and implementation of the energy-saving and emission reduction measures plan has effectively ensured the low-carbon management work of port enterprises. Affected by the epidemic, the carbon emission of Shanghai port shows a trend of first depression and then increase.

As can be seen from Table 8, the change of carbon emission in Shanghai port is basically consistent with the change of cargo throughput, showing a year-on-year growth trend. The carbon emission of diesel oil decreased from 73,300 tons in 2010 to 51,200 tons in 2019, with a cumulative decrease of $43.09 \%$ and an average annual decrease of $3.9 \%$. Carbon emissions from fuel oil increased from 33,200 tons in 2010 to 34,200 tons in 2019 , with a cumulative increase of $3.05 \% \%$ and an average annual increase of $0.35 \%$. Carbon emissions from electricity consumption increased from 262,400 tons in 2010 to 381,300 tons in 2019 , with a cumulative increase of $31.19 \%$ and an average annual growth rate of $4.24 \%$. Carbon dioxide emissions from ship activities in the port area of Shanghai Port tend to be stable and basically do not fluctuate much. Although the cargo volume in the port area has increased, Shanghai Port has actively implemented emission reduction measures to reduce carbon emissions from ships to a certain extent. The carbon emission from ships accounts for the highest proportion of carbon emission in Shanghai port, more than half of which comes from ships, with an average proportion of $58.34 \%$; followed by carbon emission from electricity consumption, with an average proportion of $31.2 \%$ in 10 years.

The total carbon emission of Shanghai port increases year by year, mainly due to the yearly growth of ship emission, electric energy consumption and fuel oil energy consumption in the port area, and the carbon emission from ships in the port area is the main source of carbon emission in the port; and the main reason for the change of carbon emission growth rate is that the energy consumption of ships in the port area grows faster, far more than the direct energy consumption, and the growth rate is faster. Electricity energy consumption ranks second after ship energy consumption. Fuel oil accounts for the smallest proportion, about $3.86 \%$ on average, and diesel $\mathrm{CO} 2$ emissions account for $6.60 \%$.

\section{Conclusion}

This paper focuses on the carbon emission measurement of Shanghai port from 2010-2019. Firstly, we determine the measurement boundary and scope of port carbon emissions. Based on the geographic location of the port area as the measurement boundary and the GHG protocol, the carbon emissions of the port are divided into three categories, including fuel combustion carbon emissions, electricity consumption carbon emissions, and port ship carbon emissions; the carbon emission measurement model of
Shanghai port is constructed by drawing on the measurement methods of other literature; the required data and information are found through the research, and the relevant data and information are organized; finally, the carbon emissions in the three ranges are measured according to the measurement model and the collected data, and the change trend and characteristics of the carbon dioxide emissions of Shanghai port are analyzed. Finally, the carbon emissions in the three ranges were measured according to the model and the collected data, and the trends and characteristics of carbon dioxide emissions in Shanghai port were analyzed. The main conclusions are as follows.

First, Ship emissions in the port area are the main source of carbon emissions in Shanghai port, followed by electricity emissions, diesel emissions, and the lowest proportion of fuel oil emissions, and their carbon emissions account for $58.34 \%$, $31.20 \%, 6.60 \%$ and $3.86 \%$ in order. The carbon emission share of ships has been maintained at a high level, with a cumulative growth of $0.43 \%$ and an average annual growth of $4.24 \%$, and the emissions far exceed other emissions. Diesel, on the contrary, has been maintaining a decreasing trend since 2012 , with annual average decrease rates of $0.43 \%, 0.72 \%$, $2.21 \%, 3.10 \%, 3.79 \%, 4.06 \%$ and $3.90 \%$ from 2012 to 2019 , respectively.

Secondly, The carbon emission of Shanghai port is consistent with the growth trend of port cargo throughput, and the overall trend is gradually rising. The change of carbon emission intensity per unit cargo throughput of port production gradually slows down in the long term, reflecting that as port enterprises continue to promote energy conservation and emission reduction and improve energy utilization, the effect of energy conservation and emission reduction becomes more obvious.

Finally, As China currently relies mainly on fossil fuels such as coal to produce electricity, the power conversion factor is large, and the energy structure does not change fundamentally in a short period of time, so the effect of reducing $\mathrm{CO}_{2}$ through shore power technology and other measures is not obvious in the short term. However, with the use of clean energy such as wind and tidal energy and the transformation of power structure, the reliance of ports on reducing carbon emissions through the adjustment of energy structure will continue to increase.

\section{Acknowledgment}

We thank Prof. J. S. Zhang,C. C. Wang, and Y. K. Lu, etc. This work was supported in part by a grant from Shanghai Maritime University.

\section{References}

[1] G. Dong. "Discussion on the growth space of cargo throughput of Shanghai port,"China Ports, vol. 4, pp. 27-28, 2013.

[2] A. Carballo-Penela, et al. "From the motorways of the sea to the green corridors' carbon footprint: the case of a port in Spain," Journal of Environmental Planning and Management, vol. 55, no. 6, pp. 765-782, Feb. 2012.

[3] G. Villalba, E. D. Gemechu, "Estimating GHG emissions of marine ports - the case of Barcelona," Energy Policy, vol. 39, no. 3, pp. 1363-1368, Mar. 2011.

[4] A. Misra, et al. "Sustainability and environmental management: Emissions accounting for ports," Strategic Planning for Energy and the Environment, vol. 37, no. 1, pp. 8-26, Feb. May. 2017. 
[5] J. H. Van, H. Geerlings, "Estimating $\mathrm{CO} 2$ footprints of container terminal port-operations," International Journal of Sustainable Development and Planning, vol. 6, no. 4, pp. 459473, 2011.

[6] M. A. Budiyanto, M H Huzaifi, et al. "Evaluation of $\mathrm{CO} 2$ emissions and energy use with different container terminal layouts," Scientific reports, vol. 11, no. 1, pp. 1-14, Feb. Mar. 2021.

[7] Y. T. Chang, Y. Song, Y. Roh, "Assessing greenhouse gas emissions from port vessel operations at the Port of Incheon," Transportation Research Part D: Transport and Environment, vol. 25, pp. 1-4, Feb. Dec. 2013.

[8] L. Goldsworthy, B. Goldsworthy, "Modelling of ship engine exhaust emissions in ports and extensive coastal waters based on terrestrial AIS data-An Australian case study," Environmental Modelling \& Software, vol. 63, pp. 45-60, Jan. 2015.

[9] M. Tichavska, B. Tovar, "Port-city exhaust emission model: An application to cruise and ferry operations in Las Palmas Port," Transportation Research Part A: Policy and Practice, vol. 78, pp. 347-360, Aug. 2015.

[10] H. Winnes, L. Styhre, E. Fridell, "Reducing GHG emissions from ships in port areas," Research in Transportation Business \& Management, vol. 17, pp. 73-82, Dec. 2015.

[11] D. O. Olukanni, C. O. Esu, "Estimating greenhouse gas emissions from port vessel operations at the Lagos and Tin Can ports of Nigeria," Cogent Engineering, vol. 5, no. 1, pp. 1507267, Aug. 2018.

[12] J. P. Jalkanen, et al. "A modelling system for the exhaust emissions of marine traffic and its application in the Baltic Sea area," Atmospheric Chemistry and Physics, vol. 9, no. 23, pp. 9209-9223, Dec. 2009.

[13] H. R. Olesen, et al. "Ship contribution to air pollution in Denmark-an assessment utilising AIS data," presented at the 13th Conference on Harmonisation within Atmospheric Dispersion Modelling for Regulatory Purposes. 2010.

[14] T. Pitana, E. Kobayashi, and N. Wakabayashi, "Estimation of exhaust emissions of marine traffic using Automatic Identification System data (case study: Madura Strait area, Indonesia)," presented at OCEANS'10 IEEE SYDNEY. IEEE, 2010.

[15] J. P. Jalkanen, et al. "Extension of an assessment model of ship traffic exhaust emissions for particulate matter and carbon monoxide," Atmospheric Chemistry and Physics, vol. 12, no. 5, pp. 2641-2659, Mar. 2012.

[16] S. K. Ng, et al. "Policy change driven by an AIS-assisted marine emission inventory in Hong Kong and the Pearl River Delta," Atmospheric environment, vol. 76, pp. 102-112, Sept. 2013.

[17] C. S. Peng, "Container Terminal Carbon Emission Accounting Methodology," Containerization, vol 7, pp. 14-17, May. 2012.

[18] Y. Zhou, et al. "Port-related emissions, environmental impacts and their implication on green traffic policy in Shanghai," Sustainability, vol. 12, no. 10, pp. 4162, May. 2020.

[19] S. S. Zhao, "Wuhan Port Carbon Emission Analysis and System Dynamics Simulation,"in China, Wuhan University of Technology, 2018.

[20] Tongji University, " Survey on Air Pollutants in Ships and Ports in Shanghai,"Shanghai Environmental Monitoring Center, Shanghai, 2014. 